\title{
Active e-learning in ophthalmology through live webinars: back to the theatre
}

\author{
Mario R. Romano ${ }^{1,2} \cdot$ Mariantonia Ferrara $\oplus^{3} \cdot$ Carlos Rocha-de-Lossada $\mathbb{1}^{4} \cdot$ Martina Angi ${ }^{5} \cdot$ Andrea Govetto $^{6,7}$. \\ Rodolfo Mastropasqua ${ }^{8} \cdot$ Vito Romano $\mathbb{1}^{9,10}$
}

Received: 8 August 2020 / Revised: 15 October 2020 / Accepted: 16 October 2020 / Published online: 28 October 2020

(c) The Royal College of Ophthalmologists 2020

\section{To the Editor:}

We read with interest the article titled "Transforming ophthalmic education into virtual learning during COVID-19 pandemic: a global perspective" by Chatziralli et al. [1]. They highlighted the need of the continuity of ophthalmology education and the crucial role that e-learning may have during pandemic [1]. In a previous survey-based study assessing the impact of pandemic on training, we outlined that the long-term reorganization of ophthalmology education can significantly benefit from technology-based teaching tools [2]. Moreover, educational activities involving learners' active participation and promoting interaction (active learning) are known to be superior to passive lecturing in terms of teaching effectiveness [3].

In this regard, we describe, for the first time, an innovative model of active e-learning in a web-based course in vitreoretinal surgery, held at Humanitas University, Milan, Italy. The course was entirely broadcast online and structured using webinars and active learning techniques (casebased discussion, pause procedures, commitment activities, open discussion) (Table 1). Ninety-nine participants

Mario R. Romano

mario.romano.md@gmail.com

1 Department of Biomedical Sciences, Humanitas University, Pieve Emanuele, Milano, Italy

2 Eye Centre, Humanitas Gavazzeni-Castelli, Bergamo, Italy

3 Newcastle Eye Centre, Royal Victoria Infirmary, Newcastle upon Tyne, UK

4 Hospital Clinic of Barcelona, Barcelona, Spain

5 Ocular Oncology Service, Melanoma and Sarcoma Unit, Department of Surgery, Fondazione IRCCS Istituto Nazionale dei Tumori, Milano, Italy (ophthalmology trainees and specialists) attended the course, of which 44 (group A) at the venue and 45 (group B) via live streaming. Lecture and surgery webinars were followed via live streaming by both groups, whereas formal lectures, case-based and open discussion sessions were attended at the venue by group A and via live streaming by group B. A course evaluation survey was conducted using a five-point scale ranging from 1 (very poor) to 5 (excellent).

Overall, the participants were highly satisfied with the course $(4.875 \pm 0.4$ in group A, $4.82 \pm 0.45$ in group B) and teaching effectiveness $(4.7 \pm 0.52$ and $4.89 \pm 0.3$ in group $\mathrm{A}$ and $\mathrm{B}$, respectively). The interaction level was highly rated regardless of attendance modality $(4.75 \pm 0.54$ in group A, $4.79 \pm 0.52$ in group B). Both groups strongly appreciated lecture and surgery webinars $(4.775 \pm 0.48$ and $4.75 \pm 0.59$ in group A, $4.84 \pm 0.43$ and $4.82 \pm 0.45$ in group B, respectively). Mean scores did not significantly differ for all the items between the groups (Table 2).

Ophthalmology active e-learning may be a promising teaching format, preserve interaction and audience engagement and, thus, improve ophthalmology education, ensuring the continuity of learning beyond any situational barriers.

6 Bristol Eye Hospital, University Hospitals Bristol NHS Foundation Trust, Bristol, UK

7 Fatebenefratelli-Oftalmico Hospital, ASST-Fatebenefratelli-Sacco, Milan, Italy

8 Department of Surgery, Medicine and Dentistry, University of Modena and Reggio Emilia, Modena, Italy

9 Department of Corneal and External Eye Diseases, St Paul's Eye Unit, Royal Liverpool University Hospital, Liverpool, UK

10 Department of Eye and Vision Science, University of Liverpool, Liverpool, UK 
Table 1 Structure of the course.

\begin{tabular}{ll}
\hline Course session $^{\mathrm{a}}$ & Description \\
\hline Formal lectures & $\begin{array}{l}\text { Topic-specific lectures of about 20-30 min including case-based presentations and } \\
\text { edited surgical video-recordings and promoting active audience participation } \\
\text { through open-ended and multiple-choice topic-specific questions }\end{array}$ \\
Open discussion & $\begin{array}{l}\text { Sessions of 20-30 min following a brief pause at the end of each formal lecture, } \\
\text { where the attendees were invited to ask questions related or not to the topic of the } \\
\text { lecture }\end{array}$ \\
Lecture-webinars & $\begin{array}{l}\text { Topic-specific lectures of about 30 min delivered by different expert instructors } \\
\text { sharing their presentations online while presenting from their own hospitals, } \\
\text { followed by 20-30 min of discussion }\end{array}$ \\
Surgery webinars & $\begin{array}{l}\text { live surgery performed by experienced surgeons from the operating theatre in their } \\
\text { own hospitals and delivered via real-time streaming. The surgeon was able to }\end{array}$ \\
interact with the audience in real-time throughout the entire surgery \\
clinical case presentations given by the participants and followed by discussion. \\
Each session included several presentations with overall duration of about 90 min.
\end{tabular}

${ }^{a}$ Each day of the course included 3 formal lectures, 3 open discussion sessions, 1 surgery-webinar, 2 lecturewebinars and 1 case-based discussion session.

Table 2 Mean scores of the course audience's survey.

\begin{tabular}{lcll}
\hline Item, mean \pm SD & Group A & Group B & $p$ value \\
\hline Overall satisfaction & $4.875 \pm 0.4$ & $4.82 \pm 0.45$ & 0.4 \\
Effectiveness of teaching & $4.7 \pm 0.52$ & $4.89 \pm 0.3$ & 0.3 \\
Influence of moderation on teaching & $4.75 \pm 0.45$ & $4.76 \pm 0.53$ & 0.3 \\
effectiveness & & & \\
Usefulness in your clinical practice & $4.7 \pm 0.56$ & $4.79 \pm 0.46$ & 0.4 \\
Clarity of the course information & $4.5 \pm 0.72$ & $4.69 \pm 0.61$ & 0.1 \\
Structure of the course sessions & $4.65 \pm 0.53$ & $4.61 \pm 0.59$ & 0.8 \\
Interaction & $4.75 \pm 0.54$ & $4.79 \pm 0.52$ & 0.6 \\
-Effectiveness of discussion & $4.675 \pm 0.57$ & $4.69 \pm 0.52$ & 0.9 \\
-Active audience participation & $4.575 \pm 0.63$ & $4.59 \pm 0.63$ & 0.8 \\
-Ease of interaction with teachers & $4.575 \pm 0.59$ & $4.72 \pm 0.51$ & 0.2 \\
Lectures (formal and webinar) & $4.775 \pm 0.48$ & $4.84 \pm 0.43$ & 0.4 \\
-Scientific content & $4.875 \pm 0.33$ & $4.77 \pm 0.48$ & 0.3 \\
-Duration & $4.75 \pm 0.49$ & $4.64 \pm 0.53$ & 0.2 \\
-Availability for discussion & $4.725 \pm 0.55$ & $4.6 \pm 0.64$ & 0.3 \\
Surgery-webinars & $4.75 \pm 0.59$ & $4.82 \pm 0.45$ & 0.7 \\
-Surgical level & $4.725 \pm 0.64$ & $4.58 \pm 0.72$ & 0.2 \\
-Quality of videos & $4.35 \pm 0.8$ & $4.36 \pm 0.74$ & 0.9 \\
-Understanding of surgical plan/steps & $4.75 \pm 0.44$ & $4.61 \pm 0.54$ & 0.2 \\
-Availability for discussion & $4.55 \pm 0.68$ & $4.84 \pm 0.43$ & $0.02 *$ \\
\hline
\end{tabular}

$S D$ standard deviation.
Acknowledgements The authors thank Hannah Levis for proofreading this manuscript.

\section{Compliance with ethical standards}

Conflict of interest The authors declare that they have no conflict of interest.

Publisher's note Springer Nature remains neutral with regard to jurisdictional claims in published maps and institutional affiliations.

\section{References}

1. Chatziralli I, Ventura CV, Touhami S, Reynolds R, Nassisi M, Weinberg $\mathrm{T}$, et al. Transforming ophthalmic education into virtual learning during COVID-19 pandemic: a global perspective. Eye. 2020:1-8. https://doi.org/10.1038/s41433-020-1080-0.

2. Ferrara M, Romano V, Steel DH, Gupta R, Iovino C, van Dijk EHC, et al. Reshaping ophthalmology training after COVID-19 pandemic. Eye. 2020;34:2089-97.

3. Subramanian A, Timberlake M, Mittakanti H, Lara M, Brandt ML. Novel educational approach for medical students: improved retention rates using interactive medical software compared with traditional lecture-based format. J Surg Educ. 2012;69:449-52. 